\title{
Hyperphosphatemia Promotes Senescence of Myoblasts by Impairing Autophagy Through Ilk Overexpression, A Possible Mechanism Involved in Sarcopenia
}

\author{
Patricia Sosa $^{1}$, Elena Alcalde-Estevez ${ }^{1,2}$, Patricia Plaza ${ }^{1}$, Nuria Troyano ${ }^{1}$, Cristina Alonso ${ }^{3}$, \\ Laura Martínez-Arias ${ }^{4}$, Andresa Evelem de Melo Aroeira1, Diego Rodriguez-Puyol ${ }^{2,5,6}$, Gemma \\ Olmos $^{1,6,}$, , Susana López-Ongil 2,6, \#, María P. Ruíz-Torres ${ }^{1,6, \#}$ \\ ${ }^{1}$ System Biology Department, Alcala University, Alcalá de Henares, Madrid, Spain. \\ ${ }^{2}$ Research Unit, Biomedical Research Foundation from Príncipe de Asturias University Hospital, Alcalá de \\ Henares, Madrid, Spain. \\ ${ }^{3}$ Geriatric and Frailty Section, Getafe University Hospital, Getafe, Madrid, Spain. \\ ${ }^{4}$ Bone and Mineral Research Unit, Hospital Universitario Central de Asturias. Instituto de Investigación \\ Sanitaria del Principado de Asturias, Red de Investigación Renal (REDinREN] del ISCIII, Oviedo, Spain \\ ${ }^{5}$ Nephrology Section, Biomedical Research Foundation from Principe de Asturias University Hospital, Alcalá de \\ Henares, Madrid, Spain \\ ${ }^{6}$ Instituto Reina Sofía de Investigación Nefrológica, IRSIN, Madrid, Spain.
}

[Received September 12, 2017; Revised December 12, 2017; Accepted December 14, 2017]

\begin{abstract}
In mammalians, advancing age is associated with sarcopenia, the progressive and involuntary loss of muscle mass and strength. Hyperphosphatemia is an aging-related condition involved in several pathologies. The aim of this work was to assess whether hyperphosphatemia plays a role in the age-related loss of mass muscle and strength by inducing cellular senescence in murine myoblasts and to explore the intracellular mechanism involved in this effect. Cultured mouse $\mathrm{C}_{2} \mathrm{C}_{12}$ cells were treated with $10 \mathrm{mM}$ beta-glycerophosphate (BGP] at different periods of time to induce hyperphosphatemia. BGP promoted cellular senescence after $24 \mathrm{~h}$ of treatment, assessed by the increased expression of p53, acetylated-p53 and p21 and senescence associated $\beta$ galactosidase activity. In parallel, BGP increased ILK expression and activity, followed by mTOR activation and autophagy reduction. Knocking-down ILK expression increased autophagy and protected cells from senescence induced by hyperphosphatemia. BGP also reduced the proliferative capacity of cultured myoblasts. Old mice (24months-old] presented higher serum phosphate concentration, lower forelimb strength, higher expression of p53 and ILK and less autophagy in vastus muscle than young mice (5-months-old]. In conclusion, we propose that hyperphosphatemia induces senescence in cultured myoblasts through ILK overexpression, reducing their proliferative capacity, which could be a mechanism involved in the development of sarcopenia, since old mice showed loss of muscular strength correlated with high serum phosphate concentration and increased levels of ILK and $\mathbf{p 3 3 .}$
\end{abstract}

Key words: hyperphosphatemia, senescence, myoblasts; ILK, autophagy, sarcopenia

Aging is a multifactorial phenomenon characterized by the progressive deterioration of physiological functions, which increases the susceptibility of the organism to many diseases and death [1]. In mammalians, advancing age is associated with sarcopenia, the progressive and involuntary loss of muscle mass and strength [2].

*Correspondence should be addressed to: Dr. Gemma Olmos, Facultad de Medicina y Ciencias de la Salud, Universidad de Alcalá. Alcalá de Henares, 28871 Madrid, Spain. E-mail: gemma.olmos@uah.es. "These authors contributed equally to this work.

Copyright: ( 2017 Sosa P et al. This is an open-access article distributed under the terms of the Creative Commons Attribution License, which permits unrestricted use, distribution, and reproduction in any medium, provided the original author and source are credited. 
Sarcopenia reduces independence and the quality of life for individuals, and leads to falls and fractures with escalating health costs for the rapidly aging human population. The sarcopenic muscle is characterized by atrophy of type II fibers, changes and heterogeneity in fiber size, accumulation of fat and connective tissue between the fibers, decline in mitochondrial metabolism and in its oxidative capacity, increased inflammation and protein catabolism [3, 4]. Sarcopenia is also related to a reduction in the number and function of satellite cells, the myogenic stem cells, inside fibers, which can compromise the regenerative capacity of the aged muscle [5). In resting muscle, satellite cells are quiescent and become activate after injury or growth stimulus. Activated satellite cells, which are called myoblast, proliferate massively to generate the myogenic progenitors needed for muscle regeneration or can return to a quiescent state to maintain the satellite cell pool. In this case, cell fate decisions are regulated by intrinsic or extrinsic factors present in the microenvironment of the satellite cell niche [6). The intracellular mechanism underlying the progressive loss of muscle function has not been completely elucidated yet, and hence, there has been a growing interest in the study of the factors that play a role in the genesis of sarcopenia in order to develop new therapeutic interventions able to reduce or to slow down ageassociated muscle wasting [7).

At cellular level, aging is known as cellular senescence, defined by Hayflick as an irreversible arrest of cell division [8). Cells come into senescence after a determined number of divisions by the telomere shortening [9], or prematurely triggered by stressful stimuli, such as activated oncogenes, DNA damage, or oxidative stress [10-12]. Senescent cells have an altered cellular morphology, increased activity of senescenceassociated- $\beta$-galactosidase (SA- $\beta$-Gal), accumulation of DNA damage foci, induction of senescence associated secretory phenotype (SASP) and loss of proteostasis [13]. With age and in some premature aging syndromes, the number of senescent cells increases in multiple tissues, disrupting tissue homeostasis and contributing to its agerelated dysfunction [14].

Cellular senescence is induced in different cellular types by changes in several environmental and systemic factors. Among others, hiperosmolarity, high glucose [15], glycated albumin [16] and hyperphosphatemia [17] have been described as inductors of cellular senescence. Recent studies have analyzed the role of elevated serum phosphate concentration in aging-related pathologies [18]. Regulation of the serum phosphate level is dependent on dietary phosphate intake, intestinal absorption and renal excretion. Renal and intestinal management of phosphate is mainly regulated by $\mathrm{PTH}$, Vitamin D, the Fibroblast Growth Factor 23 (FGF23), and
Klotho [19]. Mice lacking Klotho or FGF23 exhibit a premature aging syndrome associated with abnormal mineral metabolism characterized by hyperphosphatemia, hypercalcemia, and hypervitaminosis D [20]. Several genetic and dietary interventions to reduce serum phosphate rescue the premature aging syndrome, suggesting a primary role of hyperphosphatemia in premature aging. The effect of high extracellular phosphate concentration has been studied in several cell types. Recent studies suggest that it induces changes in cellular phenotype, including osteoblast mineralization and differentiation [21], osteaoclast differentiation [22] and calcification of vascular smooth muscle [23]. Since the FGF23 KO mice and the Klotho mice exhibited severe muscle wasting [20], we wondered whether hyperphosphatemia could directly affect the skeletal muscle cells, leading to sarcopenia.

Besides, cellular senescence is regulated by conserved intracellular signaling pathways and an emerging role of integrin linked kinase (ILK) in the aging process has been recently described [24]. ILK is a component of the multiprotein transmembrane complex mediating integrin-dependent signalling. ILK has serinethreonine kinase activity and it links the actin cytoskeleton and other intracellular signalling pathways with the extracellular matrix [25, 26]. ILK regulates proliferation, migration and other cellular functions, but only a few works describe a relationship with the aging process. Increased expression of ILK and fibronectin and $\beta 1$ integrin expression have been described in old rats [27]. In cultured cells, ILK overexpression induced senescence-associated alteration in aging cardiac fibroblasts [28], whereas genetic reduction of ILK in C. elegans and Drosophyla extended lifespan [29]. Also, we have recently demonstrated that ILK overexpression reduced the expression of Klotho in cultured renal cells [30].

The aim of the present work was to assess whether hyperphosphatemia plays a role in the age-related loss of mass muscle and strength by inducing cellular senescence in murine myoblasts and to explore the intracellular mechanism involved in this effect.

\section{MATERIALS AND METHODS}

\section{Materials}

Culture media Dulbecco's modified Eagle's medium (DMEM) was from Lonza (Basel, Switzerland). Foetal bovine serum (FBS), antibiotics, OptiMEM and antiGAPDH antibody were from Life Technologies Ltd., (Carlsbad, CA, USA). Culture plates and blueStarprestained protein marker were from Cultek (Thermo Fisher Scientific brand, Madrid, Spain), and 
Chemiluminescence reagent detection system was from Pierce (Thermo Fisher Scientific brand, Madrid, Spain). The fluorogenic ImaGene green $\mathrm{C}_{12} \mathrm{FDG}$ (5-dodecanoylaminofluorescein di-ß-D-galactopyranoside) substrate reagent and ProLong ${ }^{\circledR}$ Gold antifade reagent with DAPI were from Molecular Probes (Thermo Fisher Scientific brand, Madrid, Spain). Acrylamide-bisacrylamide was from Hispanlab-Pronadisa (Madrid, Spain). Protein Assay for measurement protein concentration, electrophoresis equipment and PVDF membrane were from Bio-Rad Laboratories (Richmond, CA, USA). Protease inhibitor cocktail tablets and 5-Bromo-2-deoxy-uridine (BrdU) were from Roche Diagnostics S.L. (Barcelona, Spain). Fluorescein isothiocyanate (FITC)-conjugated anti-BrdU was from Becton-Dickinson (San Jose, CA, USA). The secondary horseradish peroxidase-conjugated goat antimouse $\operatorname{IgG}$ and antirabbit IgG was from Dako (Glostrup, Denmark). Antibodies against phosphoGSK3 $\beta$ (Ser9), GSK3 $\beta$, ILK1, acetyl-p53 (Lys382), phospho-S6 Ribosomal protein (Ser235/236), S6 Ribosomal protein, SQSTM1/p62 and LC3B were from Cell Signalling Technology (IZASA, Barcelona, Spain). Anti-PCNA (PC10), small RNA interference (siRNA) against ILK and Silencer negative control (scrambled) were from Santa Cruz Biotech (Sta. Cruz, CA, USA). Anti-p21 antibody was from BD Biosciences (Erembodegem, Belgium). Anti-myosin heavy chain (MHC) was from R\&D System (Minneapolis, MN, USA) and desmin was from Abcam (Cambridge, UK). QuantiChrom phosphate assay kit (DIPI-500) was from Bioassay System (Hayward, CA, USA). Metafectene transfection reagent was from Biontex Laboratories (Munich, Germany). Beta-glycerophosphate (BGP), rapamycin, phosphonoformic acid (PFA), anti-p53 antibody, chloroquine, and the rest of drugs or reagents (unless otherwise indicated) were from Sigma-AldrichFluka Chemical Co. (St. Louis, MO, USA).

\section{Cell culture}

$\mathrm{C}_{2} \mathrm{C}_{12}$, a mouse myoblast cell line, was from American Type Culture Collection (Manassas, VA, USA). Cells were grown in Dulbecco's Modified Eagle Media (DMEM) containing $4.5 \mathrm{~g} / \mathrm{L}$ glucose and supplemented with $10 \% \mathrm{FBS}, 100 \mathrm{U} / \mathrm{mL}$ penicillin and $100 \mu \mathrm{g} / \mathrm{mL}$ streptomycin in an atmosphere of $95 \%$ air and $5 \% \mathrm{CO}_{2}$. Cells were used at passages 3-10.

\section{Animal studies}

Five- and twenty-four-month-old male C57BL6 mice were obtained from Janvier Laboratories. Animals were kept on a $12: 12 \mathrm{~h}$ light-dark cycle, at $24^{\circ} \mathrm{C}$, and food and water were available ad libitum. Then, mice were anesthetized, and blood samples were collected by heart puncture exsanguinations. Skeletal muscle was obtained and conserved in RNA later solution for protein extraction. Serum phosphate was measured by a commercial kit according to manufacturer instructions.

The study design and the experimental protocols were performed in agreement with the Guide for the Care and Use of Laboratory Animals published by the US National Institute of Health (NIH Publication No.85-23, revised 1996) and with the European Union regulations (EU Directive 2010/63/EU). The study was revised and approved in accordance with the Ethics Committee from Alcala University for mice (Madrid, Spain).

\section{Forelimb grip strength test}

To measure forelimb grip strength, we used a Grip Strength Meter (UGO BASILE) from PSYMTEC (Madrid, SPAIN). The procedure was as follows: grip strength was measured by gently pulling the mouse by the tail in a horizontal plane parallel with the base plate of the grip strength meter. The animal's grip strength was measured as peak force registered. Each mouse was tested ten times consecutively per day at one-minute intervals, with the maximum grip strength used in analyses. The order of mice tested by this test was randomized. All investigators were blinded to all results. Test sessions were performed during the afternoon hours of the light cycle (11 AM to $14 \mathrm{PM}$ ).

\section{Protein extraction and immunoblot analysis}

After treatments, cells were washed twice with cold PBS and lysed in buffer $(10 \mathrm{mM}$ Tris- $\mathrm{HCl} \mathrm{pH} 7.4,1 \mathrm{mM}$ EDTA, $1 \%$ Triton X-100, 0.1\% sodium deoxycholate) containing a protease inhibitor cocktail. The resulting solution was spun at $13,000 \mathrm{rpm}$ for $30 \mathrm{~min}$ at $4{ }^{\circ} \mathrm{C}$. Protein concentration was determined with BioRad protein assay kit. Proteins samples were run onto 8-12\% SDS-polyacrylamide gels (PAGE) under reducing conditions and then transferred onto PVDF membranes. Membranes were blocked with 5\% non-fat milk in Tween Tris buffered saline (TTBS) (20mM Trizma, $\mathrm{pH} 7.6$, $150 \mathrm{mM} \mathrm{NaCl}, 0.05 \%$ Tween-20) for $1 \mathrm{~h}$ at room temperature $(\mathrm{R} / \mathrm{T})$, and incubated with the corresponding primary antibodies overnight at $4^{\mathrm{a}} \mathrm{C}$ and then incubated with secondary antibodies at room temperature for $1 \mathrm{~h}$. The immunoreactive bands were visualized with the chemiluminescence reagent detection system and densitometrically analysed by using Image J software 2.6. Then, blots were reblotted with a mouse anti-GAPDH antibody in order to normalize protein levels.

Quantitative RT-PCR 
Total RNA from $\mathrm{C}_{2} \mathrm{C}_{12}$ cells was isolated using TRIzol reagents according to the manufacturer's protocol. cDNA was synthesized using a High-Capacity cDNA reverse transcription kit (Applied Biosystems Inc., Foster City, CA, USA), the gene expression was measured by quantitative PCR (ABI Prism 7500 Fast Real-Time PCR System) and analyzed with 7500 Fast sequence detection software v1.3.1 (Applied Biosystems Inc., Foster City, CA, USA), using TaqMan and SYBR green genes and Double delta $\mathrm{Ct}$ method. TaqMan genes: MCP1 (Mm00441242_m1) and the endogenous control betaactin (Mm00607939_s1). SYBR green primers: IL6 (from 5 to 3), forward: CCG GAG AGG AGA CTT CAC AGA GGA, and reverse: AGC CTC CGA CTT GTG AAG TGG TAT A; TNF $\alpha$ (from 5 to 3), forward: TGG CCC AGA CCC TCA CAC TCA, and reverse: GGC TCA GCC ACT CCA GCT GC and the endogenous control glyceraldehyde-6-phosphate dehydrogenase (GAPDH) (from 5 to 3), forward: CCA CCC AGA AGA CTG TGG AT, and reverse: CACATT GGG GGT AGG AAC AC.

\section{Detection of senescence-associated $\beta$-galactosidase activity by fluorescence confocal microscopy}

$\mathrm{C}_{2} \mathrm{C}_{12}$ cells were grown in microscope cover glasses and after $24 \mathrm{~h}$ of free-serum DMEM, they were treated with BGP, at different times, in the presence or not of different antagonists. To determine cellular senescence, SA- $\beta$ GAL activity was measured by fluorescence confocal microscopy, using the fluorogenic substrate $\mathrm{C}_{12} \mathrm{FDG}$ (Dimri et al., 1995). After BGP treatment, $33 \mu \mathrm{M} \mathrm{C}_{12} \mathrm{FDG}$ was added for $4 \mathrm{~h}$. At the end of incubation, cells were washed twice with PBS, and fixed with $4 \%$ paraformaldehyde for $15 \mathrm{~min}$. Subsequently, cells were washed again and mounting in ProLong ${ }^{\circledR}$ Gold antifade reagent with DAPI overnight. Samples were analyzed using LEICA TCS-SP5 confocal microscope (Leica Microsystems; GmbH, Mannheim, Germany) at $488 \mathrm{~nm}$ argon laser to detect green fluorescence of SA-B-GAL activity and at $405 \mathrm{~nm}$ to detect DAPI. Pictures were obtained, and fluorescence intensity was measured by densitometry by Image J software (http://rsbweb.nih.gov/ ij/).

\section{$\mathrm{C}_{2} \mathrm{C}_{12}$ differentiation assay}

Cells were grown in microscope cover glasses during seven days with $2 \%$ horse serum to promote myogenic differentiation, in the presence or the absence of $10 \mathrm{mM}$ BGP.

To determine myotube formation, myosin heavy chain (MHC) and desmin expression were assessed by immunofluorescence using a confocal microscopy. After BGP treatment, cells were washed twice with PBS, and fixed with $4 \%$ paraformaldehyde for $15 \mathrm{~min}$ at $\mathrm{R} / \mathrm{T}$, then $0.5 \%$ Triton $\mathrm{X}-100$ was added for $10 \mathrm{~min}$ at $\mathrm{R} / \mathrm{T}$. After that, cells were blocked with 5\% BSA for $1 \mathrm{~h}$ at R/T, and then incubated first, with rabbit anti-desmin (1:500) overnight in a humid chamber at $4^{\circ} \mathrm{C}$, and second, with mouse anti-MHC (1:100) for $2 \mathrm{~h}$ at $\mathrm{R} / \mathrm{T}$. After being washed in PBS, cells were incubated $1 \mathrm{~h}$ with a mix of 200-fold diluted goat anti-rabbit IgG labelled with Alexa Fluor 488 to detect desmin in green and 200-fold diluted goat anti-mouse IgG labelled with Alexa Fluor 647 to detect MHC in red. Finally, cover glasses were mounted on ProLong Gold antifade reagent with DAPI to stain nuclei in blue overnight. Preparations were visualized in confocal microscope LEICA TCS-SP5. Fluorescence intensity from pictures obtained was measured by Image J software.

\section{Transient transfection experiments}

ILK was silenced in $\mathrm{C}_{2} \mathrm{C}_{12}$ cells by transfecting a specific small RNA interference (siRNA) against ILK (siILK, Santa Cruz). To knockdown expression of ILK, we used a mixture of three oligonucleotides ILK siRNA. An unspecific scramble was used as transfection control. Transfections were performed using the Metafectene reagent and OptiMEM for $24 \mathrm{~h}$. After transfections, cells were incubated with complete DMEM for $24 \mathrm{~h}$. After that, $10 \mathrm{mM}$ BGP was added in some wells for $48 \mathrm{~h}$ using serum free DMEM. Afterward, cells were processed for checking ILK and, then, p53, p62 and pS6 protein expression, as described above.

\section{In vitro wound healing model}

The monolayer of cultured cells $\mathrm{C}_{2} \mathrm{C}_{12}$ was scratched with a needle to give a $0.6 \mathrm{~mm}$ wide wound, washed and cultured in culture media with $10 \mathrm{mM}$ BGP for $20 \mathrm{~h}$ or 24 h. Images of wound areas were captured with Moticam microscope (Motics Microscopes). The scratch wound area was measured using Image Plus Software, and percentage of wound closure at each time point was derived by the following formula [31]:

(1- [current wound size/initial wound size]) x100.

\section{Cell proliferation assay by BrdU incorporation}

Cell proliferation was assessed by BrdU incorporation into cellular DNA according to the manufacturer's instructions. After cell treatment, BrdU was added for the following $24 \mathrm{~h}$. The level of BrdU cell incorporation was detected in cells labelled with propidium iodine and FITC-conjugated anti-BrdU monoclonal antibodies, analyzed at $488 \mathrm{~nm}$ on a FACScan flow cytometer (Becton-Dickinson). 
A
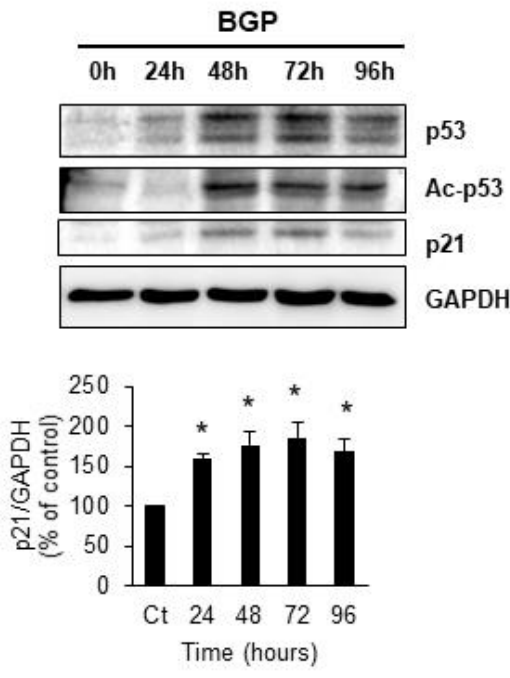

B

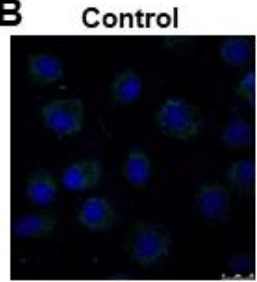

BGP 48h
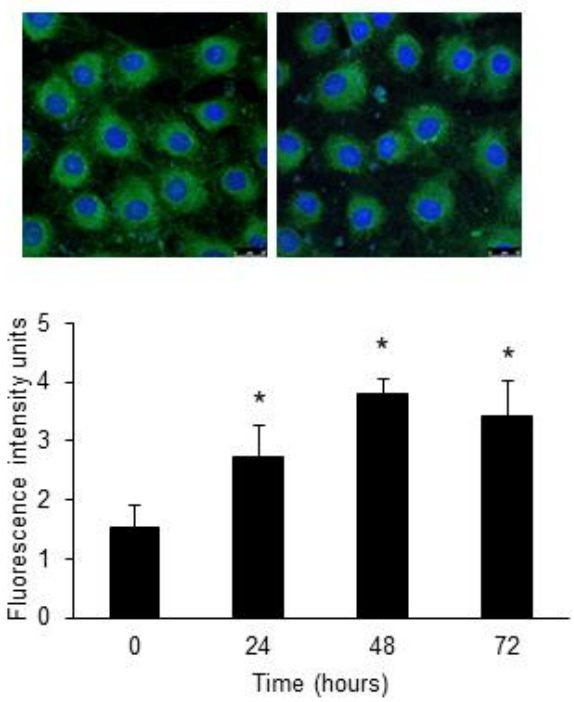

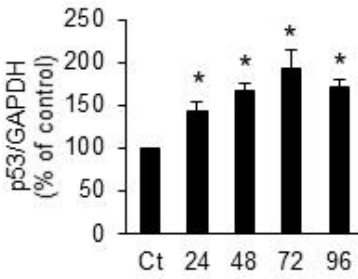

Time (hours)

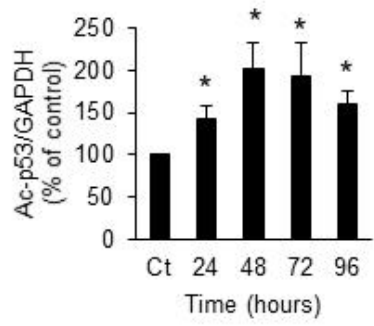

C
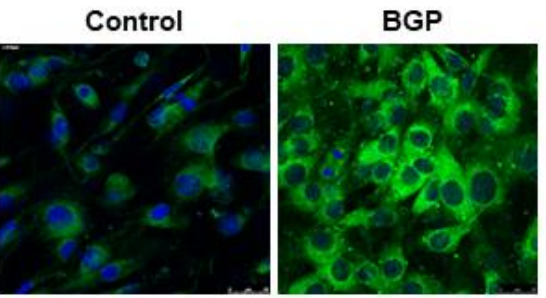

PFA

PFA+BGP
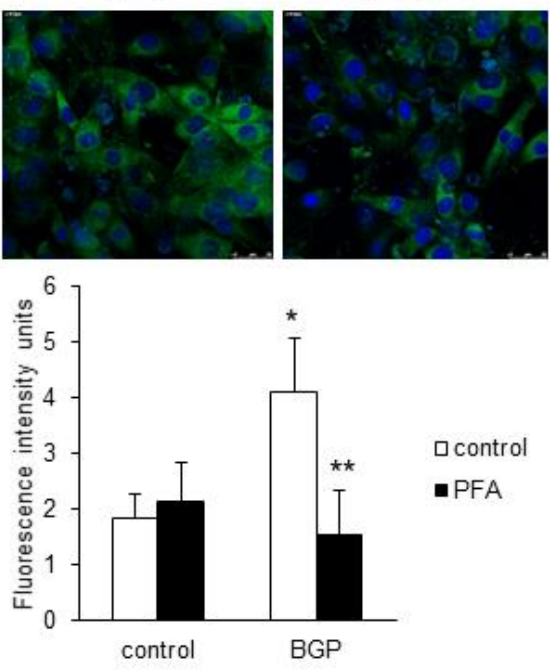

口control

- PFA

Figure 1. Hyperphosphatemia induces senescence in $\mathbf{C}_{2} \mathbf{C}_{12}$ cells. Cultured $\mathrm{C}_{2} \mathrm{C}_{12}$ were treated with 10 mM BGP for 24, 48, 72 and 96 hours. A) Acetylated-p53 (Ac-p53), p53 and p21 expression were analysed by western blot. A representative blot is shown in each case. Bar graphs represent the densitometric analysis of the bands. The results are expressed as a percentage of control cells (time $0 \mathrm{~h}$ ) and are the mean \pm standard error of the mean from five different experiments. * $p<0.05$ vs control). B) Senescence associated $\beta$ galactosidase activity was analysed by confocal microscopy using the fluorogenic substrate $\mathrm{C}_{12} \mathrm{FDG}$ after 24, 48 and 72 hours $10 \mathrm{mM}$ BGP incubation. C) $\mathrm{C}_{2} \mathrm{C}_{12}$ were treated with $10 \mathrm{mM}$ BGP or vehicle for 48 hours in the presence or the absence of phosphonoformic acid $(0.5 \mathrm{mM}, \mathrm{PFA})$ and senescence associated $\beta$ galactosidase activity was evaluated as above. In $\mathbf{B}$ and $\mathbf{C}) \mathrm{A}$ representative experiment is shown in each case. Bar graphs represent the densitometric analysis of the fluorescence of 20 cells. Results are expressed as arbitrary fluorescence intensity units and are the mean \pm standard error of the mean from five different experiments. $* \mathrm{p}<0.05$ vs control. ** $\mathrm{p}<0.05$ vs BGP. 


\section{Statistical analysis}

Results are expressed as the mean \pm standard error of the mean of an independent variable number of experiments detailed in figure captions and as a percentage of the control values. GraphPad Prism 5 and Stata Software were used for statistical analysis. The following statistical tests were used: one-way or two-way ANOVA followed by
Dunnett test for all experiments but wound healing experiments which were analysed using a repeated measures multilevel lineal model with treatment, time and time by treatment interaction test. Experiments performed in animals were analysed by an unpaired t-test with Welch's correction. The level of statistical significance was defined as $\mathrm{p}<0.05$.

A
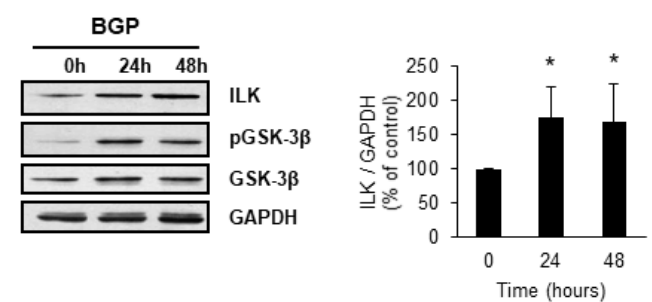

B
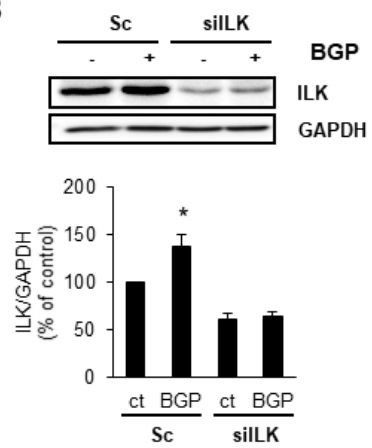

D

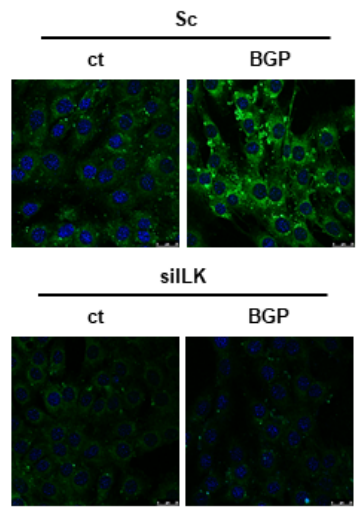

C
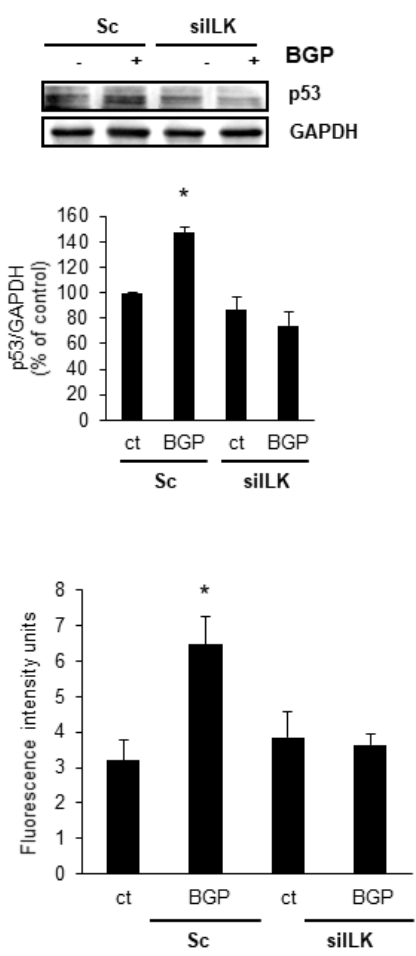

Figure 2. Hyperphosphatemia induces senescence by increasing ILK expression and activity. A) $\mathrm{C}_{2} \mathrm{C}_{12}$ were treated with 10 $\mathrm{mM}$ BGP for 24 or 48 hours, then, ILK, phospho-GSK3 $\beta$ (pGSK-3 $\beta$ ) and total GSK3 $\beta$ were analysed by western blot. $\mathbf{B}$ and $\mathbf{C}$ ) $\mathrm{C}_{2} \mathrm{C}_{12}$ were transfected with the specific siRNA against ILK (siILK) or unspecific siRNA as a control (scramble) and treated for 48 hours with $10 \mathrm{mM}$ BGP. ILK (B) and p53 (C) expression was evaluated by western blot. A representative blot is shown in each case. Bar graphs represent the densitometric analysis of the bands. The results are expressed as a percentage of control and are the mean \pm standard error of the mean from four different experiments. ${ }^{*} \mathrm{p}<0.05$ vs control. D) $\mathrm{C}_{2} \mathrm{C}_{12}$ were transfected with the specific siRNA against ILK (siILK) or unspecific siRNA as a control (scramble) and treated for 48 hours with $10 \mathrm{mM}$ BGP. Senescence associated $\beta$ galactosidase activity was analysed by confocal microscopy using the fluorogenic substrate $\mathrm{C}_{12} \mathrm{FDG}$. Bar graph represents the densitometric analysis of the fluorescence of 20 cells. Results are expressed as arbitrary fluorescence intensity units and are the mean \pm standard error of the mean from four different experiments. $* \mathrm{p}<0.05$ vs control.

\section{RESULTS}

\section{Hyperphosphatemia induces senescence in $C_{2} C_{12}$ cells by increasing ILK expression and activity}

Cultured murine $\mathrm{C}_{2} \mathrm{C}_{12}$ cells were depleted of FBS during $24 \mathrm{~h}$ and then treated with $10 \mathrm{mM}$ BGP as phosphate donor for different periods of time and the content of acetylated-p53, p53 and p21 was evaluated by western blot. BGP induced a significant increased expression of all proteins after $24 \mathrm{~h}$ of treatment (Fig. 1A) which remained elevated until $96 \mathrm{~h}$ of treatment. No changes were found in p16 expression (data not shown). Cellular senescence was also evaluated as SA- $\beta-$ Gal staining by confocal microscopy. The fluorescent signal was increased $24 \mathrm{~h}$ after BGP addition and remained elevated until $72 \mathrm{~h}$ (Fig. 1B). We analysed the senescence associated secretory phenotype (SASP) of $\mathrm{C}_{2} \mathrm{C}_{12}$ cells after BGP treatment by testing mRNA expression of some pro-inflammatory cytokines such as IL-6, TNF- $\alpha$ and 
MCP-1 by RT-qPCR. Results showed a significant increase in the mRNA expression of IL-6, TNF- $\alpha$ and MCP-1 in a time-response way (Supplemental Fig. A, B and $C$, respectively). SA- $\beta$-Gal activity was also analysed after $48 \mathrm{~h}$ incubation of BGP in the presence or the absence of PFA, an inhibitor of the Na-Pi transporter (Pit1). PFA blocked the senescence induced by BGP (Fig. 1C), suggesting a specific effect of phosphate on senescence.

Cells treated with $10 \mathrm{mM}$ BGP increased ILK expression after $24 \mathrm{~h}$ of incubation, analysed by western blot. Also, the ILK activity, assessed by the increment in phosphorylation of GSK-3 $\beta$, was increased without significant changes in the total GSK3 $\beta$ content (Fig. 2A).
To establish a relationship between the increment in ILK and cellular senescence induced by BGP, we knocked down ILK expression using a specific RNA interference. After transfection with siILK, ILK expression was reduced by fifty per cent with respect to cells transfected with scramble RNA. Similarly, ILK expression did not increase after $48 \mathrm{~h}$ incubation with BGP (Fig. 2B). p53 expression was analysed in cells transfected with siILK or scramble and results showed that knocking down ILK prevented the BGP-induced increased expression of p53 after $48 \mathrm{~h}$ of treatment (Fig. 2C). Neither did SA- $\beta$-Gal activity increase after $\mathrm{BGP}$ treatment in $\mathrm{C}_{2} \mathrm{C}_{12}$ cells transfected with siILK (Fig. 2D). These results suggest that senescence induced by hyperphosphatemia was dependent on ILK overexpression.
A
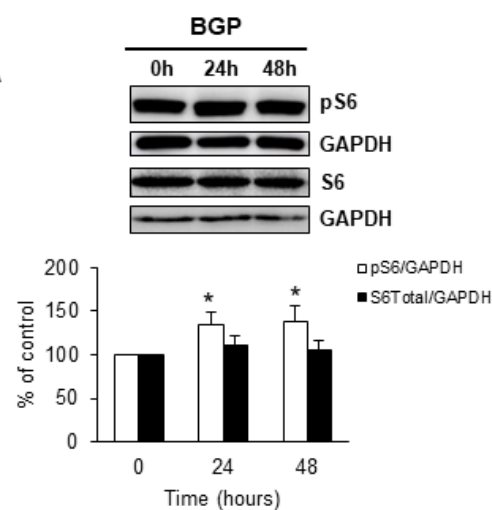

C

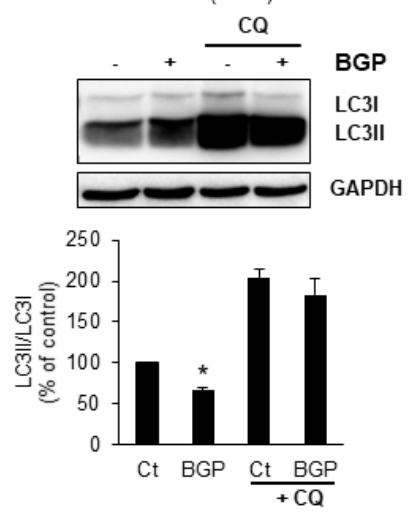

$\mathbf{E}$

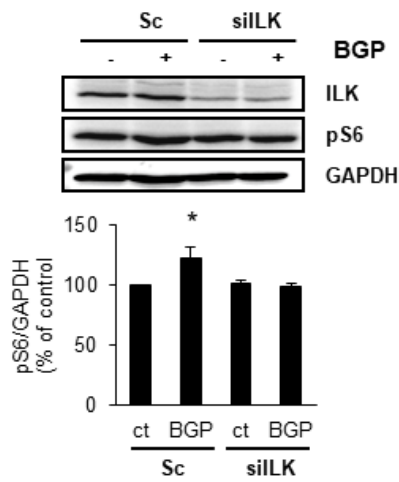

B
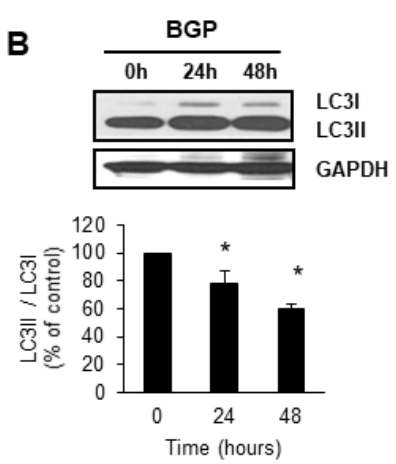

D

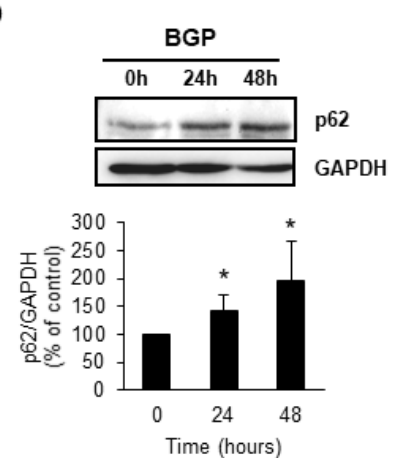

$\mathbf{F}$
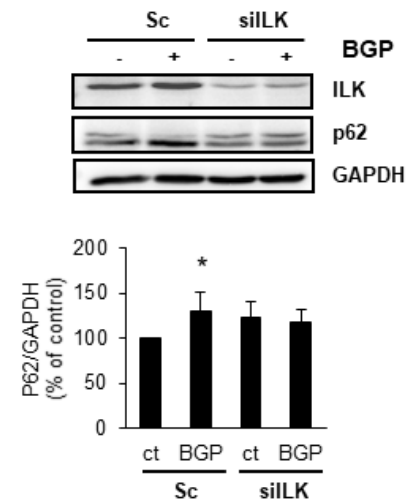

Figure 3. Hyperphosphatemia activates mTOR and reduces autophagy in myoblast through ILK activation. $\mathrm{A}, \mathrm{B}$ and $\mathrm{D}) \mathrm{C}_{2} \mathrm{C}_{12}$ cells were incubated with $10 \mathrm{mM}$ BGP for 24 or 48 hours, and with or without chloroquine

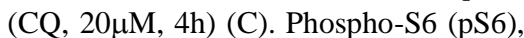
the mTOR substrate, and total S6 (S6) (A), ratio LC3II/LC3I (B and C) and p62 (D) protein expression were evaluated by western blot. A representative blot is shown in each case. Bar graphs represent the densitometric analysis of the bands. The results are expressed as a percentage of control and are the mean \pm standard error of the mean from four different experiments. $*$ p $<0.05$ vs control. $\mathbf{E}$ and F) $\mathrm{C}_{2} \mathrm{C}_{12}$ were transfected with the specific siRNA against ILK (silLK) or unspecific siRNA as a control ( $\mathrm{Sc}$, scramble) and treated for 48 hours with $10 \mathrm{mM}$ BGP. Then, ILK and pS6 (E) and ILK and p62 (F) were analysed by western blot. A representative blot is shown in each case. Bar graphs represent the densitometric analysis of the bands. The results are expressed as a percentage of control and are the mean \pm standard error of the mean from five different experiments. $* \mathrm{p}<0.05$ vs control. 


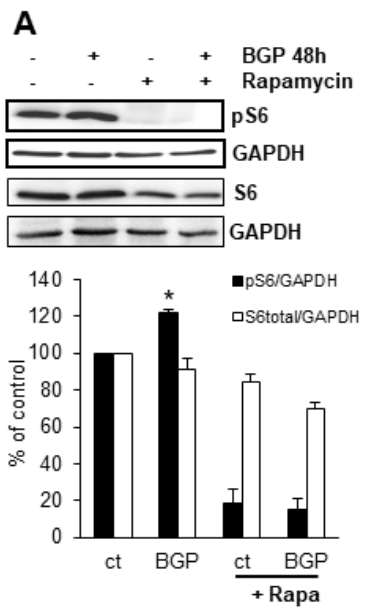

B
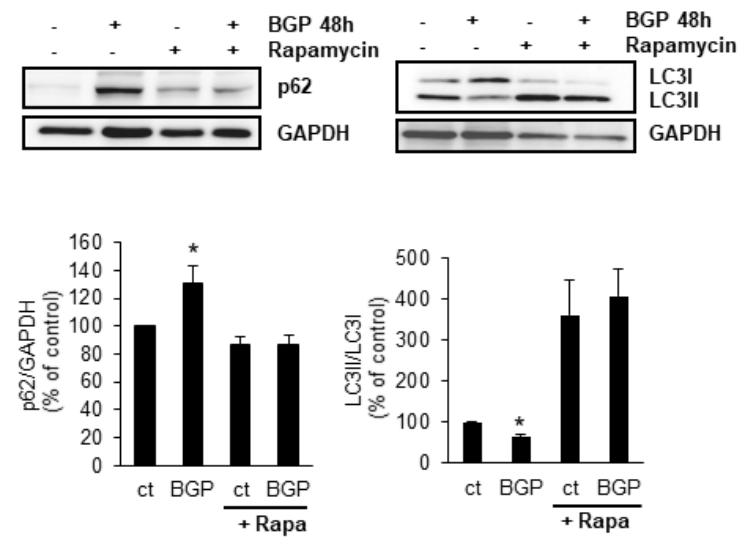

C
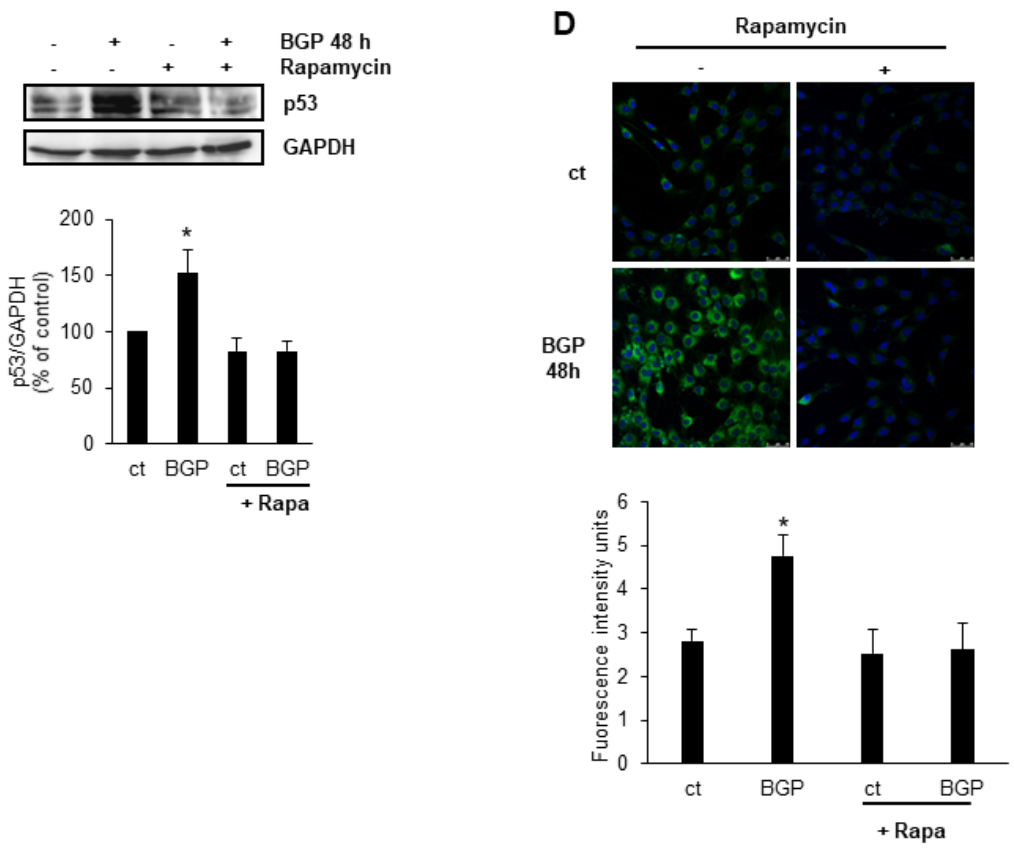

Figure 4. Inhibition of mTOR with rapamycin increases autophagy and protects myoblast from BGP-induced senescence. $\mathrm{C}_{2} \mathrm{C}_{12}$ cells were treated with $10 \mathrm{mM}$ BGP in the presence or the absence of $50 \mathrm{nM}$ Rapamycin for 48 hours. Phospho-S6 expression (pS6) (A), LC3II/LC3I ratio and p62 expression (B) and $\mathrm{p} 53$ expression $(\mathbf{C})$ were analysed by western blot. A representative blot is shown in each case. Bar graphs represent the densitometric analysis of the bands. The results are expressed as a percentage of control and are the mean \pm standard error of the mean from five different experiments. * p 0.05 vs control. D) $\mathrm{C}_{2} \mathrm{C}_{12}$ were treated with 48 hours with 10 $\mathrm{mM}$ BGP in the presence or the absence of $50 \mathrm{nM}$ rapamycin. Senescence associated $\beta$-galactosidase activity was analysed by confocal microscopy using the fluorogenic substrate $\mathrm{C}_{12}$ FDG. Bar graph represents the densitometric analysis of the fluorescence of 20 cells. Results are expressed as arbitrary fluorescence intensity units are the mean \pm standard error of the mean from four different experiments. ${ }^{*} \mathrm{p}<0.05$ vs control.

\section{Hyperphosphatemia activates mTOR and reduces autophagy in myoblast through ILK activation}

To explore the intracellular mechanisms involved in senescence induced by hyperphosphatemia, we analysed the activation of mTOR and the autophagic flux in the presence of $10 \mathrm{mM}$ BGP. Results showed that BGP increased mTOR activity significantly after $24 \mathrm{~h}$ of treatment without changes in total S6 content, assessed by the phosphorylation of S6 (Fig. 3A). Autophagy was measured by the ratio LC3II/LC3I. As presented in Fig. $3 \mathrm{~B}$, the ratio LC3II/LC3I was decreased after $24 \mathrm{~h}$ and remained until $48 \mathrm{~h}$ of BGP treatment. To analyse autophagic flux we analysed not only the ratio LC3II/LC3I in the presence or the absence of chloroquine
(20 $\mu \mathrm{M}, 4 \mathrm{~h}$ ), to block autophagy activity; but also, the accumulation of p62 in cells treated with BGP. Results showed that choroquine induced autophagosome accumulation (Fig. 3C). p62 was also significantly increased at all incubation times tested, indicating that hyperphosphatemia was reducing the autophagic flux of myoblasts (Fig. 3D). To determine whether ILK was involved in the effect of BGP on mTOR activity and autophagy, we analysed phosphorylation of S6 and p62 accumulation in $\mathrm{C}_{2} \mathrm{C}_{12}$ cells transfected with siILK or with scramble and treated with BGP for $48 \mathrm{~h}$, finding that the increases in pS6 (Fig. 3E) and p62 (Fig. 3F) were prevented when ILK expression was knocked down. 


\section{A}

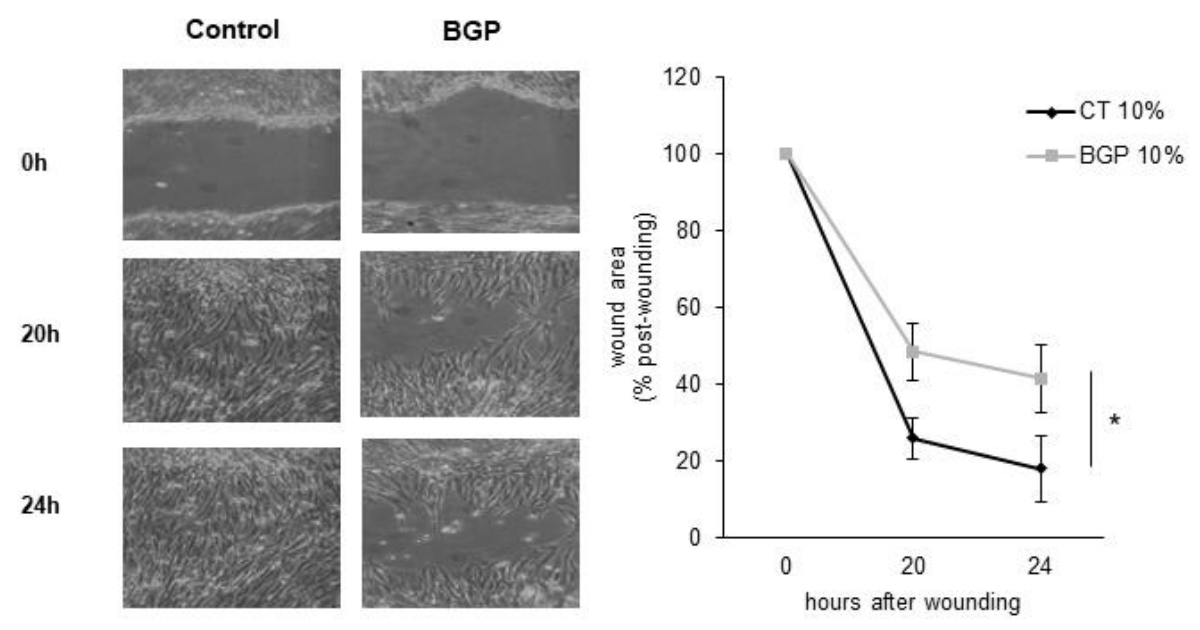

B
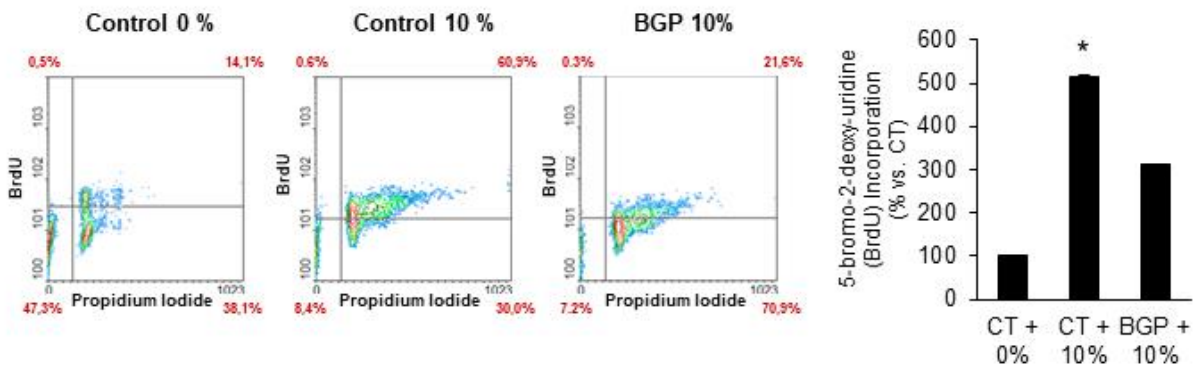

C
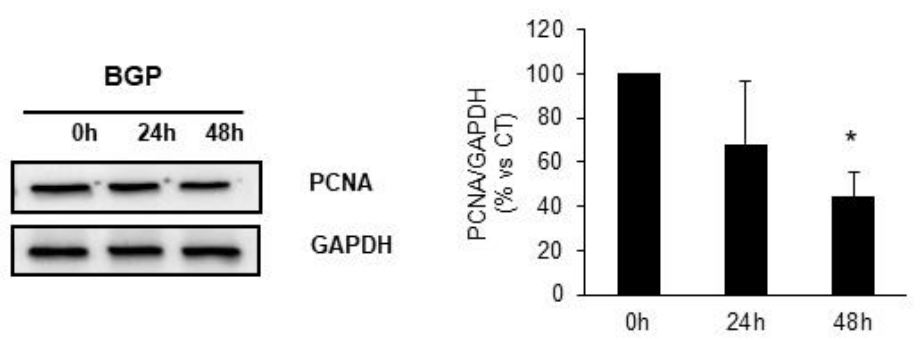

Figure 5. Hyperphosphatemia reduces proliferation of myoblasts. A) $\mathrm{C}_{2} \mathrm{C}_{12}$ growing in DMEM supplemented with $10 \%$ FBS were treated with $10 \mathrm{mM}$ BGP or vehicle for 48 hours. After that, confluent monolayers were scratch wounded. Photographs of wounds were captured at 0,20 and 24 hours post-wounding to determine the degree of wound closure. A representative experiment is shown. Graphs represent the percentage of control (time $0 \mathrm{~h}$ ) wound area at different times post-wounding. Results are mean \pm SEM from five experiments. $* \mathrm{p}=0.021$ between control and BGP treatment. B) $\mathrm{C}_{2} \mathrm{C}_{12}$ were grown in DMEM with (10\%) or without (0\%) FBS and with $10 \mathrm{mM}$ BGP for 48 hours. BrdU incorporation during the following 24 hours was evaluated by flow cytometry. Bar graph represents the percentage of proliferating cells with respect to the control cells growing in DMEM without FBS. Results are mean \pm SEM from six experiments. * $\mathrm{p}<0.05$ vs control $0 \%$. C) $\mathrm{C}_{2} \mathrm{C}_{12}$ cells were grown in DMEM supplemented with $10 \%$ FBS and treated with $10 \mathrm{mM}$ BGP for 24 and 48 hours. PCNA expression was evaluated by western blot. A representative blot is shown. Bar graph represents the densitometric analysis of the bands. The results are expressed as a percentage of control and are the mean \pm SEM from five different experiments. * $\mathrm{p}<0.05$ vs control. 
A
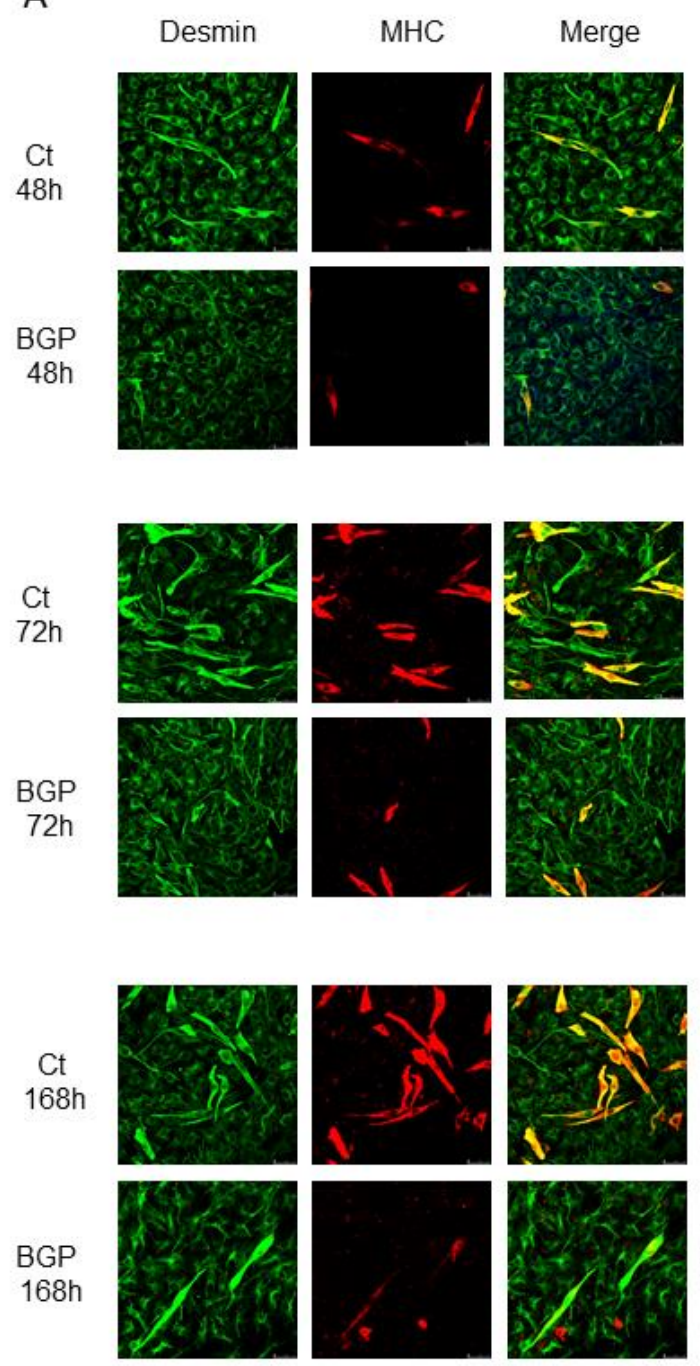

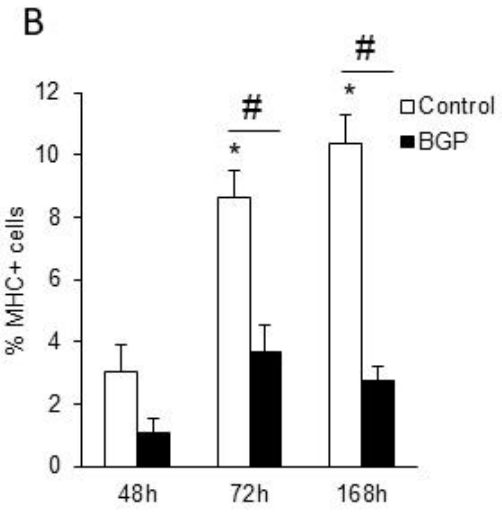

C
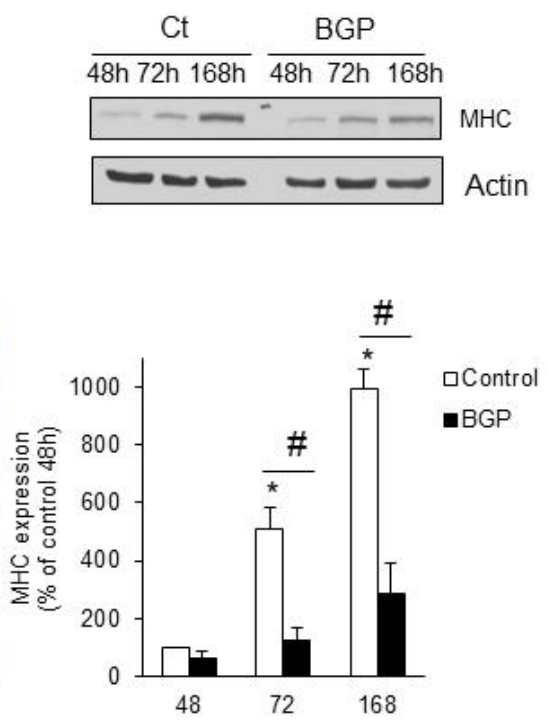

Figure 6. Hyperphosphatemia impairs myogenic differentiation of myoblasts. $\mathrm{C}_{2} \mathrm{C}_{12}$ were grown with $2 \%$ horse serum for 48,72 and 168 hours to promote myogenic differentiation. A) Myosin heavy chain (MHC, red) and desmin (green) were analysed by immunofluorescence with specific antibodies using a confocal microscopy. B) MHC positive cells were counted and represented in a bar graph. Results are mean \pm SEM from three experiments. $* \mathrm{p}<0.05$ vs control $48 \mathrm{~h}$. $\# \mathrm{p}<0.001$ vs control at the same time. C) MHC expression was evaluated by western blot. A representative blot is shown. Bar graphs represent the densitometric analysis of the bands. Results are mean \pm SEM from three experiments. $* \mathrm{p}<0.05$ vs control $48 \mathrm{~h}$. \#p $<0.001$ vs control at the same time.

Inhibition of mTOR with rapamycin increases autophagy and protects myoblast from BGP-induced senescence

To analyse whether mTOR activation was determining in BGP-induced senescence, we treated myoblast with 10 $\mathrm{mM}$ BGP during $48 \mathrm{~h}$ in the presence or the absence of the mTOR inhibitor, rapamycin. As it is shown in Fig. 4A, rapamycin completely abolished mTOR activity assessed by pS6 protein content. In these conditions, also the expected decrease in autophagy promoted by BGP, assessed by the decrease in LC3II/LC3I ratio and the p62 accumulation, was abrogated in the presence of rapamycin (Fig. 4B). In addition, rapamycin prevented the increase in p53 (Fig. 4C) and the increase in SA- $\beta-G a l$ activity (Fig. 4D) induced by BGP treatment for $48 \mathrm{~h}$, suggesting that senescence induced by BGP depends on mTOR activation and autophagy reduction. 
A

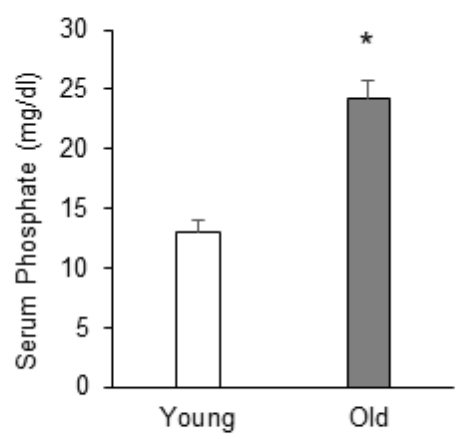

C
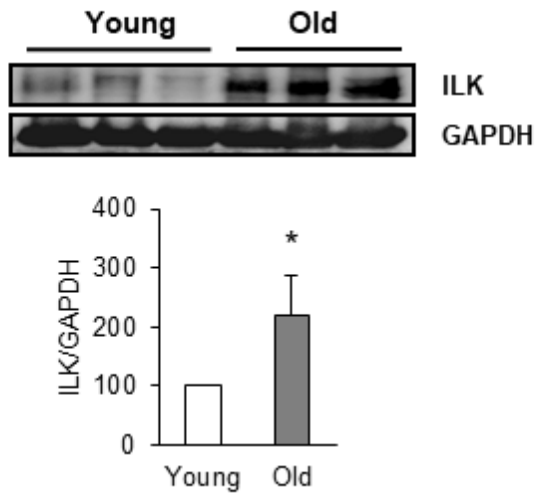

E

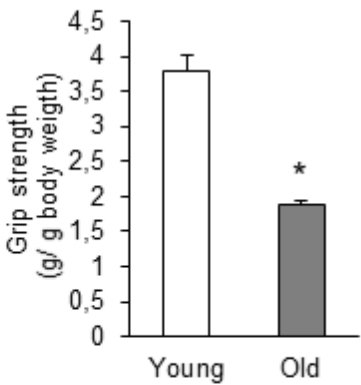

B

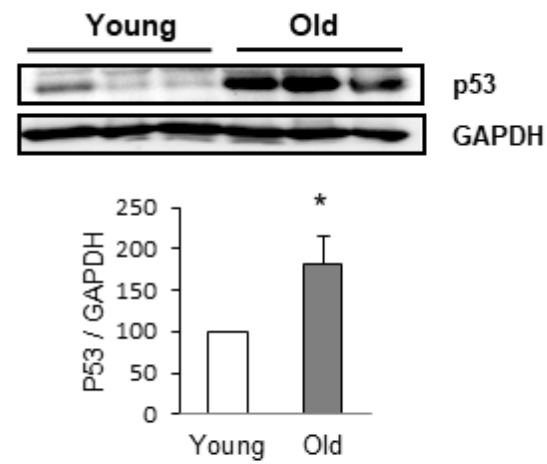

D
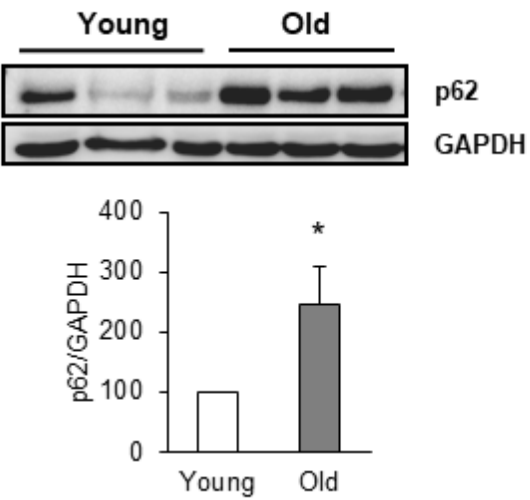
senescence genes and loss of muscle strength. Twenty-four-month-old mice (Old) were compared with five-month-old ones (Young). A) Serum phosphate concentration was assessed by a colorimetric method. Graph represents the mean \pm SEM from values obtained from 10 animals per group. $* p<0.05$ vs young. B-D) p53 (B), ILK (C) and p62 (D) expression was evaluated by western blot in protein extracts isolated from vastus from old and young mice. A representative blot is shown in each case. Bar graphs represent the densitometric analysis of the bands. The results are expressed as a percentage of young mice and are the mean \pm SEM from ten animals per group. $* \mathrm{p}<0.05$ vs young. E) Forelimb grip strength test was performed in young and old mice. Results are mean \pm SEM from ten animals per group. $* p<0.05$ vs young. 


\section{Hyperphosphatemia reduces proliferation of cultured myoblasts}

We analysed the effect of hyperphosphatemia on the proliferative capacity of myoblast. For this purpose, we performed three different approaches. First, cultured $\mathrm{C}_{2} \mathrm{C}_{12}$ cells were subjected to scratch wound healing assay in the presence or the absence of $10 \mathrm{mM}$ BGP using $10 \%$ FBS to stimulate proliferation. We observed a delay in the closure of the wound in cells treated with BGP as compared with cells growing in control conditions (Fig. 5A). Second, we analysed BrdU incorporation into DNA in cultured cells by flow cytometry. We compared cells growing in DMEM without FBS with cells growing in DMEM with $10 \%$ FBS in the presence or the absence of $10 \mathrm{mM}$ BGP during $48 \mathrm{~h}$. Results showed that BGP reduced BrdU incorporation significantly compared to cells growing in DMEM with 10\% FBS without BGP (Fig. 5B). Finally, we analysed the expression of PCNA (proliferating cell nuclear antigen) in cultured cells growing in DMEM supplemented with 10\% FBS and treated with $10 \mathrm{mM} \mathrm{BGP}$ at indicated times and we found a progressive decline in PCNA expression in the presence of BGP (Fig. 5C). After that, we concluded that hyperphosphatemia was limiting the proliferative capacity of cultured myoblasts.

\section{Hyperphosphatemia impairs myogenic differentiation of myoblast}

To promote $\mathrm{C}_{2} \mathrm{C}_{12}$ myogenic differentiation cells were growth with $2 \%$ horse serum during seven days in the presence or the absence of $10 \mathrm{mM}$ BGP. The expression of MHC was recorded at $48 \mathrm{~h}, 72 \mathrm{~h}$ and $168 \mathrm{~h}$ of treatment. As it can see in Fig. 6A and 6B, BGP significantly diminished the number of MHC positive cells indicating a reduction in myotube formation. The expression of MHC was also analysed by western blot (Fig. 6C).

\section{In vivo evidences for the role of hyperphosphatemia in skeletal muscle senescence}

To analyse the in vivo relevance of our findings, aged mice (24-months-old) were tested to determine whether, compared to young mice (5-months-old), phosphate serum was increased coinciding with the presence of senescence markers in skeletal muscle. As it is shown in Figure 7A, phosphate serum concentration was elevated in aged mice compared to young mice. Then, we analysed p53 expression in vastus muscle isolated from old and young mice, finding a significant increase in $\mathrm{p} 53$ protein content in the muscle from old mice (Fig. 7B) by comparison with young mice. Besides, ILK expression (Fig. 7C) and p62 accumulation (Fig. 7D) were also increased in vastus muscle from old mice, indicating that the intracellular mechanisms elicited by hyperphosphatemia in myoblasts were also modified in vivo.

To analyse the impact of hyperphosphatemia and senescence markers in the muscle function, we performed an analysis of the maximal and explosive force production by the forelimb grip strength test in young and old mice. Compared to young mice, the grip strength was significantly lower in all 24-month-old mice (Fig. 7E), whereas no differences were found in body mass and in muscle mass between both groups. Serum phosphate levels were significantly negatively correlated with muscle force (Pearson $\mathrm{r}=0.52, \mathrm{p}=0.0008$ ), suggesting that a cause-effect relationship could be established between hyperphosphatemia and loss of muscle force (Fig. 8).

\section{DISCUSSION}

Sarcopenia is a geriatric syndrome characterized by the loss of muscle function. The factors that initiate and maintain sarcopenic process remain to be elucidated at this moment. In this regard, a role has been described for the increased circulating levels of tumor necrosis factoralpha (TNF- $\alpha$ ), interleukin-6 (IL-6), interleukin-1 (IL-1), and $\mathrm{C}$-reactive protein (CRP) present in the elderly [32] linked with a progressive increase in glucocorticoid and catecholamine levels. Decline in sexual hormones and rise in inflammatory cytokines are also directly associated with muscle mass loss and muscle strength reduction in the elderly [33]. We propose here hyperphosphatemia as one of the systemic factors involved in the genesis of sarcopenia.

Sarcopenia is accompanied by a significant decline in satellite cell function and cell number, which compromises the regenerative capacity of aged muscle [5]. It has been proposed that satellite cells from old mice exposed to a young environment can be rejuvenated [34], indicating that there are systemic factors inducing the dysfunction found in satellite cells with advanced age. Our results demonstrate that hyperphosphatemia induces cellular senescence in cultured myoblast and also reduces proliferative capacity and the myogenic differentiation which are probably mechanisms involved in the loss of muscular mass and strength.

The increase in serum phosphate levels has been related to aging and to the increase in morbi-mortality in chronic kidney disease patients [35]. Muscle wasting is present in both, aging and chronic kidney disease patients [36]. Serum phosphate levels inversely correlate with the lifespan of diverse species [37] and hyperphosphatemia has been linked with premature aging phenotype in Klotho deficient mice and in FGF23 KO mice [19, 20]. In vitro studies have demonstrated that the increase in 
extracellular phosphate concentration modifies the behaviour of cultured cells by inducing osteogenic and osteoclastic differentiation or cellular senescence in smooth muscle cells $[21,17]$. It is the first time that the potential role of hyperphosphatemia in modifying myoblast cell cycle has been shown. To perform the experiments, we used murine $\mathrm{C}_{2} \mathrm{C}_{12}$, the most commonly used myogenic cell line. Due to the difficulty to culture and maintain primary satellite cells, $\mathrm{C}_{2} \mathrm{C}_{12}$ cells have been extensively used since their cell signalling responses remain sufficiently similar to those of primary embryonic and adult myoblasts [38]. On the other hand, $\mathrm{C}_{2} \mathrm{C}_{12}$ cells have been widely used in cellular senescence related studies [39]. $\mathrm{C}_{2} \mathrm{C}_{12}$ cells were exposed to high extracellular phosphate concentration by adding the phosphate donor BGP, as previously described [17, 40]. To assess whether phosphate entered the myoblast to perform its effect, we used a specific inhibitor of the NaPi cotransporter termed PFA [41]. We found that cells did not undergo to senescence when the phosphate intake was blocked.

Cellular senescence was assessed by the increased expression of several cell cycle regulators related to senescence: acetylated p53, p53 and p21, and also by the increase in the SA- $\beta$-Gal activity, without finding changes in p16 expression. Cellular senescence promoted without p16 increment has been previously described [16]. An increased accumulation of $\mathrm{p} 21$ and $\mathrm{p} 53$ proteins has been previously described in satellite cells from old animals compared to young animals, contributing to a lower proliferation rate of these cells [42]. Cellular senescence has been identified as a mechanism involved in the genesis of the myopathy associated with muscular dystrophy mouse model [43] and related to premature muscle wasting in young mice deficient in the protein Bmi1 [44] or mutant mice carrying BubR1 hypomorphic alleles [45].

Exploring the intracellular mechanisms involved in phosphate-induced senescence of myoblasts, we found that ILK plays a critical role. ILK has a broadly expression in muscle cells. In cardiomyocytes, ILK modulates contraction [46] and, in skeletal muscle cells, it is involved in muscle hypertrophy [47], protects fibres from stress-induced damage [48] and resembles muscular dystrophy when deleted [49]. However, our results demonstrate that overexpression of ILK induced by hyperphosphatemia leads to cellular senescence. ILK has been previously related to aging [27-28] and we report here that ILK plays an essential role in senescence induced by extracellular high phosphate concentration in cultured myoblasts. ILK expression and activity, assessed by GSK3 $\beta$ phosphorylation [50], increased after phosphate addition, and the down regulation of ILK gene by small interfering RNA protected cells from phosphateinduced senescence.

A

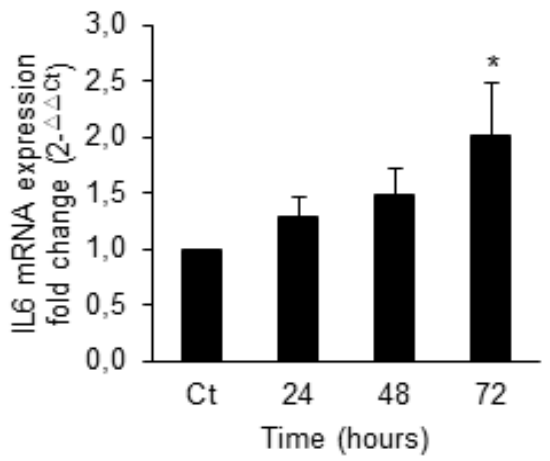

B

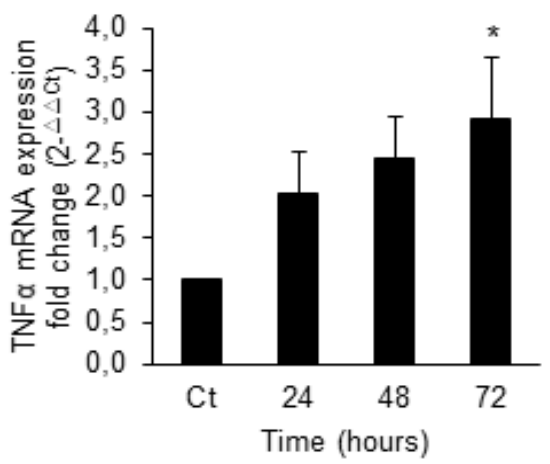

C

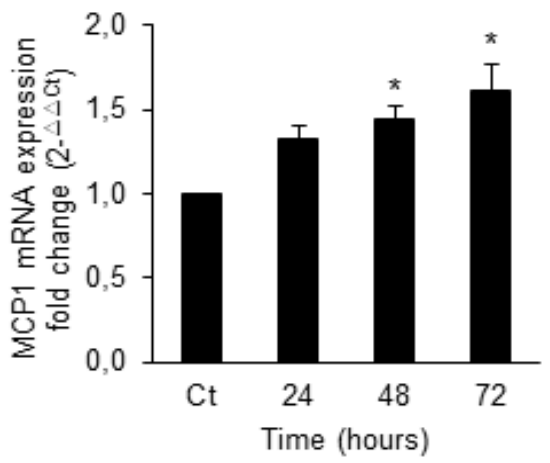

Figure 8. Hyperphosphatemia increases proinflammatory cytokine expression in $\mathrm{C}_{2} \mathrm{C}_{12}$. Cultured $\mathrm{C}_{2} \mathrm{C}_{12}$ were treated with $10 \mathrm{mM}$ BGP for 24, 48 and 72 hours. Total mRNA was isolated and IL6 (A), TNF- $\alpha$ (B) and MCP-1 (C) mRNA expression was evaluated by RT-qPCR. Results are expressed as fold change respect to control. ${ }^{*} \mathrm{p}<0.05$ vs control 
ILK is connected with numerous intracellular signalling pathways, such as the mammalian target of rapamycin (mTOR), a serine-threonine kinase, which plays an essential role in autoimmune disorders, obesity and aging [51]. We demonstrate that hyperphosphatemia induces a persistent mTOR activation, measured as the phosphorylation of ribosomal S6 protein, the substrate of p70 S6 Kinase [52], indicative of increased activation of mTOR complex1 (mTORC1), in an ILK dependent way. Persistent activation of mTOR is related to cancer, diminished cardiac performance and obesity associated metabolic diseases and has been associated with a significant reduction in autophagy [53]. Autophagy is an evolutionary conserved catabolic process, by which cytoplasmic proteins and organelles are engulfed in autophagosomes and degraded after fusion with lysosomes, preventing waste accumulation [54]. Hyperphosphatemia induces the accumulation of p62 protein and reduces the ratio LC3II/LC3I, both indicative that autophagic flux is reduced [55]. The changes in p62 and in the LC3II/LC3I ratio were inhibited with rapamycin, indicating that the reduction in autophagy was dependent on the activation of mTOR by hyperphosphatemia. Reduced autophagy induced cellular senescence in primary fibroblasts [56] and in quiescent satellite cells [57]. We demonstrate that the hyperphosphatemia is not able to induce senescence in the presence of rapamycin, indicating that the activation of mTOR and the reduction in autophagy are essential in the effect of high phosphate on senescence.

As a consequence of cellular senescence induced by hyperphosphatemia, cultured myoblasts lose their proliferative capacity and this phenomenon has been related to the development of sarcopenia. In this regard, it has been described that myostatin and activin, which are linked to sarcopenia, are also inhibitors of the myoblasts proliferation [58].

To reinforce the relevance of the effect of hyperphosphatemia in loss of skeletal muscle, we searched for evidences of senescence markers in the vastus of old mice and found a higher expression of $\mathrm{p} 53$ in muscle from old mice together with higher ILK and p62 expression, resembling the results obtained in cultured myoblast exposed to high extracellular phosphate concentration. Old mice showed a higher concentration of phosphate in serum compared to young mice. Although, a direct link between hyperphosphatemia and senescence sings in muscular tissue could not be stablished with present results, interestingly, we found that those mice with higher phosphate levels have less muscle strength in their forelimbs, measured by the grip strength test, a widely used method to assess skeletal muscle function in rodents. Old mice showed a reduction in muscle strength of about $40 \%$ compared to young mice, indicating sings of sarcopenia. In conclusion, we propose that hyperphosphatemia associated with aging could be an important inductor of sarcopenia. Our results show that high extracellular phosphate concentration induces overexpression of ILK that provokes mTOR activation and autophagy reduction, promoting cellular senescence of cultured myoblasts and reducing their proliferative capacity. This could be a mechanism involved in the development of sarcopenia associated with aging since we found loss of muscle strength in old mice in parallel with higher serum phosphate levels and expression of senescence markers, such as ILK, p53 and p62, resembling the mechanism observed in the in vitro studies. Further experiments will be necessary to demonstrate a direct cause-effect relationship between hyperphosphatemia and sarcopenia.

\section{Conflict of interest}

The authors declare that there is no conflict of interest.

\section{Acknowlegements}

This work was supported by the following grants: PI13/02270, PI13/00336, PI14/01939, PI14/02075, PI16/02082 and PI16/01619 from the Fondo de Investigaciones Sanitarias from Instituto de Salud Carlos III (ISCIII) and FEDER funds; Networks Program REDinREN from Instituto de Salud Carlos III and FEDER funds (grant RETIC REDinREN: RD12/0021/0006; RD016/0009/0018; RD12/0021/1023; RD016/0009/0017); CCG2015/BIO-024 and CCG2016/BIO-025 from University of Alcala. S. LópezOngil holds a contract from the Research Stabilization program from Instituto de Salud Carlos III (CES07/032). P. Sosa was supported by fellowship from University of Alcala. E. Alcalde was supported by fellowship from Spanish Ministry of Education. P. Plaza holds a technician fellowship from Comunidad de Madrid. PS, GO, DRP, MPR y SLO authors are part of Networks Program REDinREN. We thanks to Dr. Javier Zamora from IRYCIS for the statistical advice.

\section{References}

[1] López-Otín C, Blasco MA, Partridge L, Serrano M, Kroemer G (2013). The hallmarks of aging. Cell, 153(6):1194-217.

[2] Rosenberg IH (1997). Sarcopenia: origins and clinical relevance. J Nutr, 127 (5 (Suppl.), 990S-991S

[3] Verdijk LB, Snijders T, Beelen M, Savelberg HH, Meijer K, Kuipers H., et al. (2010). Characteristics of muscle fiber type are predictive of skeletal muscle mass and strength in elderly men. J Am Geriatr Soc, 58:2069-2075. 
[4] Nair KS (2005). Aging muscle. Am J Clin Nutri, 81:953-63

[5] Sousa-Victor P, Muñoz-Cánoves P (2016). Regenerative decline of stem cells in sarcopenia. Mol Aspects Med, 50:109-17.

[6] Dumont, NA, Wang YX, Rudnicki MA (2015). Intrinsic and extrinsic mechanism regulating satellite cell function. Development, 142:1572-1581.

[7] Grounds MD (2014). Therapies for sarcopenia and regeneration of old skeletal muscles: more a case of old tissue architecture than old stem cells. Bioarchitecture, 4(3):81-7.

[8] Hayflick L, Moorhead PS (1961). The serial cultivation of human diploid cell strains. Exp Cell Res, 25:585621

[9] von Figura G, Hartmann D, Song Z, Rudolph KL (2009). Role of telomere dysfunction in aging and its detection by biomarkers. J Mol Med, 87:1165-1171

[10] Ferbeyre G, de Stanchina E, Lin AW, Querido E, McCurrach ME, Hannon GJ et al (2002). Oncogenic ras and p53 cooperate to induce cellular senescence. Mol Cell Biol, 22:3497-3508

[11] Wang C, Jurk D, Maddick M, Nelson G, Martin-Ruiz C, von Zglinicki T (2009). DNA damage response and cellular senescence in tissues of aging mice. Aging Cell, $8: 311-323$

[12] Wei YH, Lee HC (2002). Oxidative stress, mitochondrial DNA mutation, and impairment of antioxidant enzymes in aging. Exp Biol Med, 227:671682

[13] Newgard CB, Sharpless NE (2013). Coming of age: molecular drivers of aging and therapeutic opportunities. J Clin Invest, 123:946-950

[14] Jeyapalan JC, Ferreira M, Sedivy JM, Herbig U (2007). Accumulation of senescent cells in mitotic tissue of aging primates. Mech Ageing Dev, 128:36-44

[15] del Nogal M, Troyano N, Calleros L, Griera M, Rodriguez-Puyol M, Rodriguez-Puyol D, Ruiz-Torres MP (2014). Hyperosmolarity induced by high glucose promotes senescence in human glomerular mesangial cells. Int J Biochem Cell Biol, 54:98-110.

[16] Del Nogal-Ávila M, Troyano-Suárez N, Román-García P, Cannata-Andía JB, Rodriguez-Puyol M, RodriguezPuyol D et al (2013). Amadori products promote cellular senescence activating insulin-like growth factor-1 receptor and down-regulating the antioxidant enzyme catalase. Int J Biochem Cell Biol, 45(7):125564.

[17] Troyano N, Nogal MD, Mora I, Diaz-Naves M, LopezCarrillo N, Sosa P et al., (2015). Hyperphosphatemia induces cellular senescence in human aorta smooth muscle cells through integrin linked kinase (ILK) upregulation. Mech Ageing Dev, 152:43-55.

[18] Ohnishi M, Razzaque MS (2010). Dietary and genetic evidence for phosphate toxicity accelerating mammalian aging. FASEB J, 24:3562-3571

[19] Nakatani T, Sarraj B, Ohnishi M, Densmore MJ, Taquchi T, Goetz R et al (2009). In vivo genetic evidence for klotho-dependent, fibroblast growth factor
23 (FGF23) -mediated regulation of systemic phosphate homeostasis. FASEB J, 23:433-441

[20] John GB, Cheng CY, Kuro-o M (2011). Role of Klotho in aging, phosphate metabolism, and CKD. Am J Kidney Dis, 58:127-34.

[21] Becks GR (2003). Inorganic phosphate as a signaling molecule in osteoblast differenciation. J Cell Biochem, 90:115-128

[22] Mozar A, Haren N, Chasseraud M, Louvet L, Maziere C, Wattel A et al. (2008). High extracellular inorganic phosphate concentration inhibits RANK-RANKL signaling in osteoclast-like cells. J Cell Physiol, 215:4754

[23] Jono S, McKee MD, Murry CE, Shioi A, Nishizawa Y, Mori K et al. (2000). Phosphate regulation of vascular smooth muscle cell calcification. Circ Res, 87: E10-E17

[24] Nishimura M, Kumsta C, Kaushik G, Diop SB, Ding Y, Bisharat-Kernizan J et al. (2014). A dual role for integrin-linked kinase and $\beta 1$-integrin in modulating cardiac aging. Aging Cell, 13:431-440

[25] Hannigan GE, Leung-Hagesteijn C, Fitz-Gibbon L, Coppolino MG, Radeva G, Filmus J et al. (1996). Regulation of cell adhesion and anchorage-dependent growth by a new beta 1-integrin-linked protein kinase. Nature, 379:91-96

[26] Legate KR, Montanez E, Kudlacek O, Fassler R (2006). ILK, PINCH and parvin: The IPP of integrin signalling. Nat Rev Mol Cell Biol, 7:20-31

[27] Li Z, Chen X, Xie Y, Shi S, Feng Z, Fu B, et al. (2004). Expression and significance of integrin-linked kinase in cultured cells, normal tissue, and diseased tissue of aging rat kidneys. J Gerontol A Biol Sci Med Sci, 59:984-996

[28] Chen X, Li Z, Feng Z Wang J, Ouyang C, Liu W, et al. (2006) Integrin-linked kinase induces both senescenceassociated alterations and extracellular fibronectin assembly in aging cardiac fibroblasts. J Gerontol A Biol Sci Med Sci, 61:1232-1245.

[29] Kumsta C, Ching TT, Nishimura M, Davis AE, Gelino S, Catan HH et al. (2014). Integrin-linked kinase modulates longevity and thermotolerance in C. elegans through neuronal control of HSF-1. Aging Cell, 13:419430

[30] Troyano-Suárez N, del Nogal-Avila M, Mora I, Sosa P, López-Ongil S, Rodriguez-Puyol D et al (2015). Glucose Oxidase Induces Cellular Senescence in Immortal Renal Cells through ILK by Downregulating Klotho Gene Expression. Oxid Med Cell Longev, 416738.

[31] Tan NS, Michalik L, Di-Poi N, Desvergne B, Wahli W (2004). Critical roles of the nuclear receptor PPARbeta (peroxisome-proliferator- activated receptor beta) in skin wound healing. Biochem Soc Trans, 32:97-102

[32] Visser M, Pahor M, Taaffe DR, Goodpaster BH, Simonsick EM, Newman AB et al. (2002). Relationship of interleukin-6 and tumor necrosis factor-alpha with muscle mass and muscle strength in elderly men and women: the Health ABC Study. J Gerontol A Biol Sci Med Sci, 57(5):M326-32 
[33] Rolland S, Czerwinski G, Abellan van Kan JE, Morley M, Cesari G, Onder J et al. (2008) Sarcopenia: its assessment, etiology, pathogenesis, consequences and future perspectivesy. J Nutr Health Aging, 12(7): 433450

[34] Conboy IM, Conboy MJ, Wagers AJ, Girma ER, Weissman IL, Rando TA (2005). Rejuvenation of aged progenitor cells by exposure to a young systemic environment. Nature, 433:760-764.

[35] John GB, Cheng CY, Kuro-o M (2011). Role of Klotho in aging, phosphate metabolism, and CKD. Am J Kidney Dis, 58(1):127-34.

[36] Greco A, Paroni G, Seripa D, Addante F, Dagostino MP, Aucella F (2014). Frailty, disability and physical exercise in the aging process and in chronic kidney disease. Kidney Blood Press Res, 39(2-3):164-8.

[37] Kuro-o M (2010). A potential link between phosphate and aging - lessons from Klotho-deficient mice. Mech Ageing Dev, 131(4): 270-275

[38] Cornelison DD (2008). Context matters: in vivo and in vitro influences on muscle satellite cell activity. J Cell Biochem, 105(3):663-9.

[39] Jadhav KS, Dungan CM, Williamson DL (2013). Metformin limits ceramide-induced senescence in C2C12 myoblasts. Mech Ageing Dev, 134 (11-12):54859.

[40] Chen NX, O’Neill KD, Duan D, Moe SM (2002) Phosphorus and uremic serum up-regulate osteopontin expression in vascular smooth muscle cells. Kidney Int, 62:1724-1731.

[41] Tenenhouse HS, Klugerman AH, Neal JL (1989). Effect of phosphonoformic acid, dietary phosphate and the Hyp mutation on kinetically distinct phosphate transport processes in mouse kidney. Biochim Biophys Acta, 984: 207-213

[42] Machida S, Booth FW (2004). Increased nuclear proteins in muscle satellite cells in aged animals as compared to young growing animals. Exp Gerontol, 39(10):1521-5

[43] Kudryashova E1, Kramerova I, Spencer MJ (2012). Satellite cell senescence has been related to the muscle wasting in a model of muscle dystrophy. J Clin Invest, 122(5): 1764-1776

[44] Sousa-victor P, Perdiguero E, Muñoz-canovés $P$ (2014). Geroconversión of aged muscle stem cells under regenerative pressure. Cell Cycle, 13(20):31833190.

[45] Baker DJ, Jeganathan KB, Cameron JD, Thompson M, Juneja S, Kopecka A et al. (2004). BubR1 insufficiency causes early onset of aging-associated phenotypes and infertility in mice. Nat Genet, 36(7):744-9
[46] Traister A, Li M, Aafaqi S, Lu M, Arab S, Radisic M et al. (2014). Integrin-linked kinase mediates force transduction in cardiomyocytes by modulating SERCA2a/PLN function. Nat Commun, 5:4533.

[47] Chaillou T, Lee JD, England JH, Esser KA, McCarthy JJ (2013). Time course of gene expression during mouse skeletal muscle hypertrophy. J Appl Physiol, 115(7):1065-74.

[48] Wang HV, Chang LW, Brixius K, Wickström SA, Montanez E, Thievessen I et al. (2008) Integrin-linked kinase stabilizes myotendinous junctions and protects muscle from stress-induced damage. J Cell Biol, 180(5):1037-49.

[49] Gheyara AL, Vallejo-Illarramendi A, Zang K, Mei L, St-Arnaud R, Dedhar S et al. (2007) Deletion of integrin-linked kinase from skeletal muscles of mice resembles muscular dystrophy due to alpha 7 beta 1 integrin deficiency. Am J Pathol, 171(6):1966-77

[50] Maydan M, McDonald PC, Sanghera J, Yan J, Rallis C, Pinchin $S$ et al. (2010). Integrin-Linked Kinase Is a Functional Mn2+-Dependent Protein Kinase that Regulates Glycogen Synthase Kinase-3 $\beta$ (GSK-3 $\beta$ ) Phosphorylation PLoS One, 5(8): e12356

[51] Perl A (2015). mTOR activation is a biomarker and a central pathway to autoimmune disorders, cancer, obesity, and aging. Ann N Y Acad Sci, 1346(1):33-44.

[52] Lekmine F, Uddin S, Sassano A, Parmar S, Brachmann SM, Majchrzak B et al. (2003). Activation of the p70 S6 Kinase and Phosphorylation of the 4E-BP1 Repressor of mRNA Translation by Type I Interferons. J Biol Chem, 278:27772-80

[53] Wullschleger S, Loewith R, Hall MN (2006). TOR signaling in growth and metabolism. Cel, 124(3):47184

[54] Yang Z, Klionsky DJ (2010). Eaten alive: a history of macroautophagy. Nat Cell Biol, 12(9):814-22.

[55] Gao H, Yang Q, Dong R, Hou F, Wu Y (2016). Sequential changes in autophagy in diabetic cardiac fibrosis. Mol Med Rep, 13(1):327-32.

[56] Kang HT, Lee KB, Kim SY, Choi HR, Park SC (2011). Autophagy impairment induces premature senescence in primary human fibroblasts. PLoS One, 6(8): e23367.

[57] García-Prat L, Martínez-Vicente M, Perdiguero E, Ortet L, Rodríguez-Ubreva J, Rebollo E et al (2016). Autophagy maintains stemness by preventing senescence. Nature, 529 (7584):37-42.

[58] Kalinkovich A, Livshits G (2015). Sarcopenia--The search for emerging biomarkers. Ageing Res Rev, 22:58-71. 